\title{
Diagnostic dilemma in postpartum associated hemolytic uremic syndrome in a 38th week pregnant 31-year-old Congolese: a case report
}

Marc Tshilanda ${ }^{1,2+}$, Ulrick Sidney Kanmounye ${ }^{3^{*}+}$ (D) Céline Tendobi ${ }^{1}$ and Freddy Mbuyi ${ }^{1,4}$

\begin{abstract}
Background: Thrombotic microangiopathy is associated with HELLP syndrome, thrombotic thrombocytopenic purpura, or atypical hemolytic uremic syndrome (aHUS) during pregnancy. Standard laboratory and physical examinations can help distinguish between these three diseases promptly and guide their management. This is critical because their managements and prognoses differ considerably. The ADAMTS13 test, complement tests, and biopsies can help ascertain the diagnosis; however, they take time, and are not widely available. In this case report, we present a case that highlights the diagnostic and therapeutic dilemmas associated with the aforementioned diseases.

Case presentation: A 31-year old P3G3 patient presented at 38 weeks with high blood pressure, bilateral pitting edema, and a low fetal heart rate. A cesarean section was performed to extract the fetus. On postoperative day 2 , the suites were marked by anemia, low platelet count, acute kidney injury, declining liver function, and the presence of schistocytes on the peripheral thin smear. The patient was lucid, coherent, and presented no neurological deficits. The ADAMTS13 test and anti-complement therapy were not readily available, so the team made a presumptive diagnosis of aHUS based on the history, clinical presentation, and standard laboratory results. Due to a lack of anticomplement therapy, the patient was prescribed four sessions of hemodialysis. The renal function and platelet count gradually increased, and the patient was discharged on postoperative day 18 . The patient was followed for over a year and did not present relapses of thrombocytopenia or microangiopathic hemolytic anemia.
\end{abstract}

Conclusions: The prompt diagnosis and management of aHUS lead to favorable outcomes. Healthcare providers should be able to rapidly differentiate between pregnancy-associated thrombotic microangiopathies and prescribe appropriate management. Here, we highlighted the challenges of diagnosing and managing postpartum associated aHUS in a low-resource setting.

Keywords: Atypical hemolytic uremic syndrome, Differential diagnosis, Microangiopathic hemolytic anemia, Postpartum complications, Thrombotic microangiopathy

\footnotetext{
* Correspondence: ulricksidney@gmail.com

${ }^{\dagger}$ Marc Tshilanda and Ulrick Sidney Kanmounye joint first co-authors.

${ }^{3}$ Faculty of Medicine, Université Technologique Bel Campus, Kinshasa, Democratic Republic of Congo

Full list of author information is available at the end of the article
}

(c) The Author(s). 2020 Open Access This article is licensed under a Creative Commons Attribution 4.0 International License, which permits use, sharing, adaptation, distribution and reproduction in any medium or format, as long as you give appropriate credit to the original author(s) and the source, provide a link to the Creative Commons licence, and indicate if changes were made. The images or other third party material in this article are included in the article's Creative Commons licence, unless indicated otherwise in a credit line to the material. If material is not included in the article's Creative Commons licence and your intended use is not permitted by statutory regulation or exceeds the permitted use, you will need to obtain permission directly from the copyright holder. To view a copy of this licence, visit http://creativecommons.org/licenses/by/4.0/ The Creative Commons Public Domain Dedication waiver (http://creativecommons.org/publicdomain/zero/1.0/) applies to the data made available in this article, unless otherwise stated in a credit line to the data. 


\section{Background}

Thrombotic microangiopathy (TMA) during pregnancy and the postpartum is most often associated with HELLP syndrome (hemolysis, increased liver enzymes, low platelets) or preeclampsia with severe manifestations [1-3]. Rarely, TMA may be due to thrombotic thrombocytopenic purpura (TTP), complement-mediated TMA, or atypical hemolytic uremic syndrome (aHUS). Pregnancy associated microangiopathic disorders all have distinct definitions and prognoses (Table 1). However, they are often misdiagnosed and managed inadequately.

The complexity of managing TMA cases during pregnancy is increased by a lack of expertise, tests, or equipment needed to diagnose and treat these conditions promptly. Moreover, most patients from developing countries pay for their healthcare out-of-pocket. Resultantly, clinicians in low resource settings factor nonclinical aspects when they decide on the management of their patients. This case study aims to draw attention to the difficulties associated with the diagnosis and management of pregnancy-related atypical hemolytic uremic syndrome in low-resource settings.

\section{Case presentation}

A 31-year-old black Congolese female patient, P3G3, who had a pregnancy of 38 weeks and four days, was transferred from a district hospital to a tertiary facility in Kinshasa, Democratic Republic of Congo, for severe preeclampsia with acute on chronic fetal distress. Her past medical history was notable for eclampsia during her first pregnancy in 2011 and preeclampsia in 2013 during her second pregnancy. She had had two cesarean sections for her pregnancies, and she had her antenatal care for her third pregnancy at a referral hospital. She was diagnosed with preeclampsia during her third pregnancy for which she received $250 \mathrm{mg}$ alpha-methyl-dopa twice a day. During the 30th week of gestation, the patient's systolic blood pressure became labile, oscillating between 140 and $150 \mathrm{mmHg}$, despite her antihypertension medication. The patient consulted at a district hospital where she underwent a fetal wellbeing ultrasound which did not find anomalies.

The patient was the 7 th of 9 children, and her father was hypertensive. She weighed $72 \mathrm{~kg}$ for $155 \mathrm{~cm}$, and upon arrival at the authors' hospital, her blood pressure was 217/152 mmHg. Her heart rate was $101 \mathrm{bpm}$, her respiratory rate was $24 \mathrm{cpm}$, and $\mathrm{SpO} 2$ was $96 \%$ free air. The patient was in pain, she was lucid and coherent, her palpebral conjunctivae were colored, and she had bilateral pitting edema. The fundus height was at $30 \mathrm{~cm}$, the presentation was cephalic, the fetus was bradycardic at $88 \mathrm{bpm}$, and there were no signs of genital bleeding. The cervix was median, soft, $80 \%$ effaced with a $2 \mathrm{~cm}$ dilation. Urine deep stick revealed $3+$ proteinuria. She had $1.5 \mathrm{mg} / \mathrm{dL}$ of creatinine (normal: $0.5-1.5 \mathrm{mg} / \mathrm{dL}$ ), $22 \mathrm{mg} /$ $\mathrm{dL}$ of urea (normal: 10-50 mg/dL), 15,000 white blood cells $/ \mathrm{ml}, 213,000$ platelets $/ \mathrm{ml}$ and $14 \mathrm{~g} / \mathrm{dL}$ hemoglobin. Based on these findings, we indicated an emergency cesarean section for acute fetal distress, which resulted in the extraction of a dead infant.

Postoperative suites were marked on day two by decompensated anemia (hemoglobin at $7.8 \mathrm{mg} / \mathrm{dL}$ ) for which the patient was transfused two units of packed red blood cells. On postoperative day three, the patient presented an abdominal effusion, exacerbation of the bilateral pitting edema, blood pressure increase, hematemesis, melena, petechiae, hematuria, and oliguria. Her blood pressure was 215/120 $\mathrm{mmHg}$ and she had signs of renal failure (creatinine $=6.9 \mathrm{mg} / \mathrm{dL}$ (normal: $0.84-1.21 \mathrm{mg} / \mathrm{dL}$ ); urea 132.5 $\mathrm{mg} / \mathrm{dL}$ (normal: $5-20 \mathrm{mg} / \mathrm{dL}$ ); hyperkalemia at $6.4 \mathrm{mmol} /$ L (normal: 3.5-5 mmol/L); hyponatremia $109 \mathrm{mmol} / \mathrm{L}$ (normal: $136-145 \mathrm{mmol} / \mathrm{L}$ ); hypocalcemia $0.88 \mathrm{mmol} / \mathrm{L}$ (normal: $1.12-1.32 \mathrm{mmol} / \mathrm{L}$ )), and signs of hepatic failure (AST 135 IU/L, normal: < 33 IU/L; ALT 325 IU/L, normal:

Table 1 Comparison of pregnancy-related microangiopathic disorders - atypical Hemolytic Uremic Syndrome, Hemolysis Elevated Liver enzymes, Low Platelet count, preeclampsia, and thrombotic thrombocytopenic purpura. The frequency of presentation of the characteristics are indicated in ascending order: uncommon, seldom, sometimes, frequently, and always

\begin{tabular}{|c|c|c|c|c|}
\hline Characteristic & aHUS & HELLP syndrome & Preeclampsia & TTP \\
\hline Onset & Postpartum & Third trimester & Third trimester & Throughout pregnancy and postpartum \\
\hline MAHA & Frequently & Frequently & Seldom & Always \\
\hline Thrombocytopenia & Frequently & Frequently & Seldom & Always \\
\hline Hypertension & Uncommon & Seldom & Always & Uncommon \\
\hline DIC & Seldom & Always & Seldom & Uncommon \\
\hline Liver disease & Seldom & Always & Seldom & Seldom \\
\hline Renal disease & Always & Sometimes & Sometimes & Seldom \\
\hline CNS disease & Seldom & Seldom & Seldom & Always \\
\hline Management & Anticomplement therapy & Delivery and transfusion of blood products & Delivery & Plasmapheresis \\
\hline
\end{tabular}

aHUS atypical Hemolytic Uremic Syndrome, CNS Central Nervous System, DIC Disseminated Intravascular Coagulation, HELLP Hemolysis, Elevated Liver enzymes, Low Platelet count, MAHA Microangiopathic Hemolytic Anemia, TTP Thrombotic Thrombocytopenic Purpura Com 
< 33 IU/L; prothrombin ratio 100\% (normal: 80-110\%). PTT was $39 \mathrm{~s}$ (normal: 24-35 s), LDH was $1398 \mathrm{IU} / \mathrm{L}$ (normal: 120-280 IU/L), and total bilirubin was $0.35 \mathrm{mg} /$ $\mathrm{dL}$ (normal: $0-1 \mathrm{mg} / \mathrm{dL})$ ). She equally had neutrophilic leukocytosis at 22,180 cells $/ \mathrm{mm}^{3}$ and low platelets at 44, 000 cells $/ \mathrm{mm}^{3}$. Additionally, schistocytes were identified in the peripheral thin smear.

The team excluded TTP and HELLP syndrome as possible causes of the postpartum microangiopathic hemolytic anemia (MAHA). This decision was based on the history, clinical presentation, and laboratory findings. Atypical hemolytic uremic syndrome was retained as the final diagnosis, and in the absence of anti-complement therapy, the patient underwent four sessions of hemodialysis. Hypertension was treated with Nicardipine, $5 \mathrm{mg} / \mathrm{hr}$. IV with a 2.5 $\mathrm{mg} / \mathrm{hr}$. increase every $15 \mathrm{~min}$ without exceeding $15 \mathrm{mg} / \mathrm{hr}$., and the goal was to lower the systolic blood pressure below $160 \mathrm{mmHg}$. Hyperkalemia was corrected with insulin and glucose (10 units of insulin dose with $25 \mathrm{~g}$ of glucose per each $1 \mathrm{mmol} / \mathrm{L}$ of potassium above the normal). A favorable clinical and biologic evolution was observed, and the patient was released for outpatient follow-up on postoperative day 18 (Figs. 1, 2 and 3).

Laboratory tests could not be obtained more frequently due to their financial burden to the patient and her immediate family. The patient had a normal kidney function at postoperative day 160 (urea $24.2 \mathrm{~g} / \mathrm{dL}$, creatinine $0.8 \mathrm{mg} / \mathrm{dL}$ ) and postoperative day 202 (urea 16.9 $\mathrm{g} / \mathrm{dL}$, creatinine $0.8 \mathrm{mg} / \mathrm{dL})$. She did not present new episodes of microangiopathic hemolytic anemia.

\section{Discussions and conclusions}

In low resource settings, the diagnosis and treatment of patients with MAHA-associated diseases can be challenging. While some biological tests can help confirm the diagnosis (ADAMTS13, C3b, and factor $\mathrm{H}$ ), these are often unavailable in low resource settings and can delay patient management [4]. For this reason, healthcare providers rely on the history and clinical presentation to distinguish between these diseases. For example, sudden onset of anemia, thrombocytopenia, and renal insufficiency are in favor of HELLP syndrome. Progressive worsening of the renal lesion is highly suggestive of aHUS while the presence of minimal renal insufficiency, severe thrombocytopenia with signs of neurological involvement pleads in favor of TTP [2].

Worsening clinical signs of gestational hypertension, preeclampsia, or the aggravation of anemia, thrombocytopenia, and renal function abnormalities (most common target organ damage) after delivery point towards TTP and aHUS. While minimal renal impairment with severe thrombocytopenia and neurological signs suggest TTP and the need for plasma exchange therapy, progressive renal injury (in the absence of an identifiable cause of acute tubular necrosis) suggests aHUS and the need for anti-complement treatment $[1,5]$.

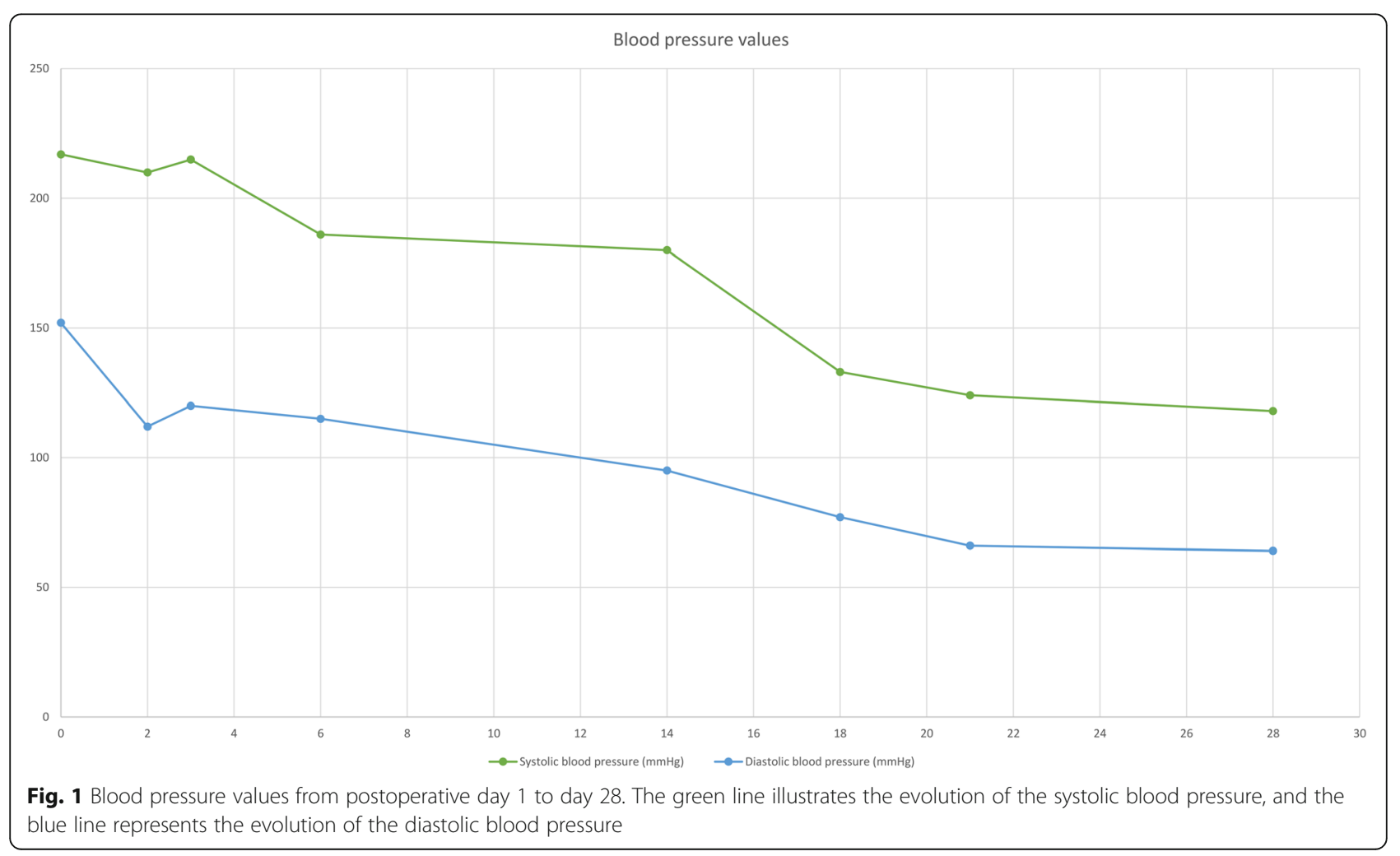




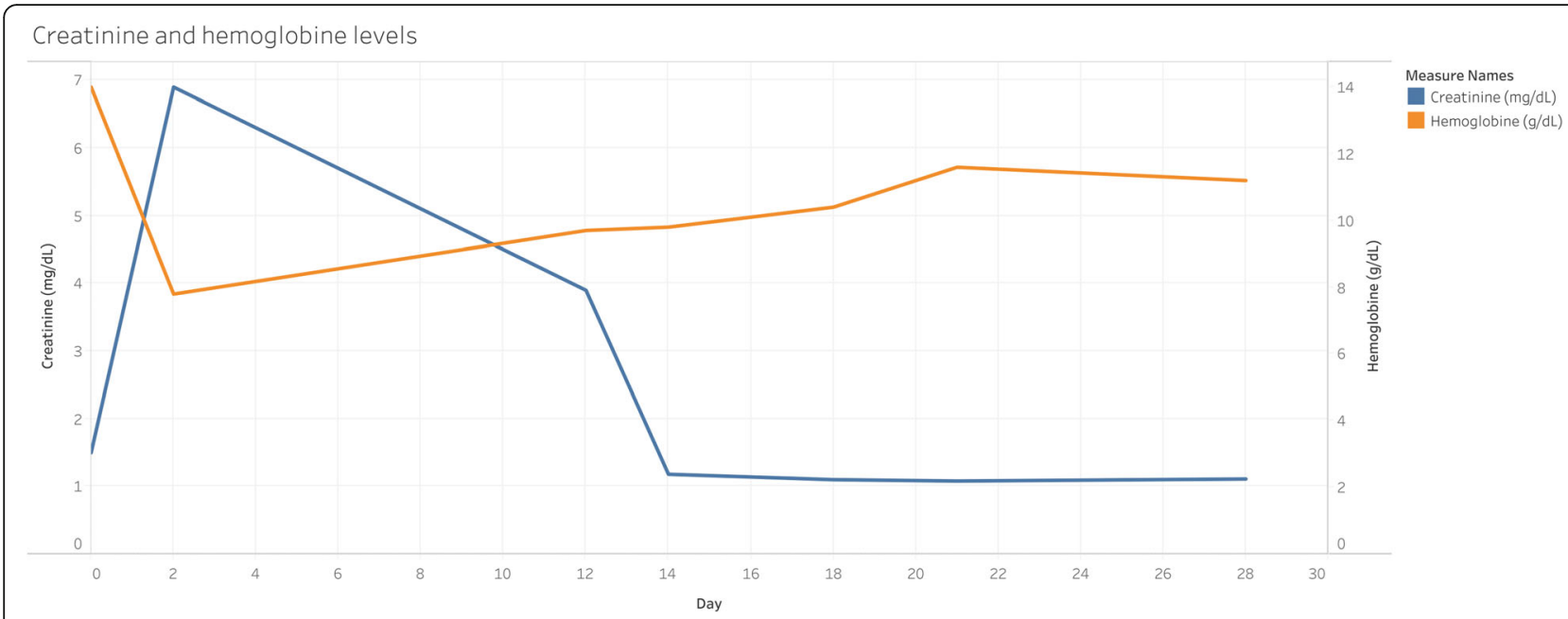

Fig. 2 Serum creatinine and hemoglobin values from postoperative day 1 to day 28. The left axis and the blue line represent the creatinine values. The right axis and the orange line represent the hemoglobin values

Unfortunately, this approach is not infallible. For example, thrombocytopenia develops in 5 to $10 \%$ of women during pregnancy or the immediate postpartum. A low platelet count is often a fortuitous feature and can, in some instances, be misleading, such as in women with coexisting systemic or gestational disorders. As a result, low platelet count might lead to an indication of a maternal intervention that can harm the fetus [6].

Given the history and presentation, in this case, there are three possible scenarios we must consider: gestational hypertension or preeclampsia triggering the complications of aHUS; gestational hypertension or preeclampsia evolving to the HELLP syndrome; or aHUS initially presenting as hypertension during pregnancy progressing to overt complications. Gestational hypertension is "hypertension that appears de novo after 20 weeks' gestation and normalizes after pregnancy". In comparison, preeclampsia is defined as "de novo hypertension after 20 weeks' gestation accompanied by at least one of the following: proteinuria, maternal organ dysfunction [renal, hepatic, neurological, and hematological] and uteroplacental dysfunction" [7]. The patient had a history of eclampsia during her first pregnancy, and she presented with bilateral pitting edema and proteinuria. Therefore, she had preeclampsia. At presentation, the patient did not have anemia or low platelets. However, more than $24 \mathrm{~h}$ after she had delivered her baby, she had hemorrhages, anemia, declining liver, and renal functions. Standard laboratory findings can help differentiate HELLP syndrome, which is a clinical presentation of severe preeclampsia from aHUS. Women with HELLP syndrome present with LDH (438$782 \mathrm{IU} / \mathrm{L})$ and creatinine $(0.7-1.1 \mathrm{mg} / \mathrm{dL})$ levels that are

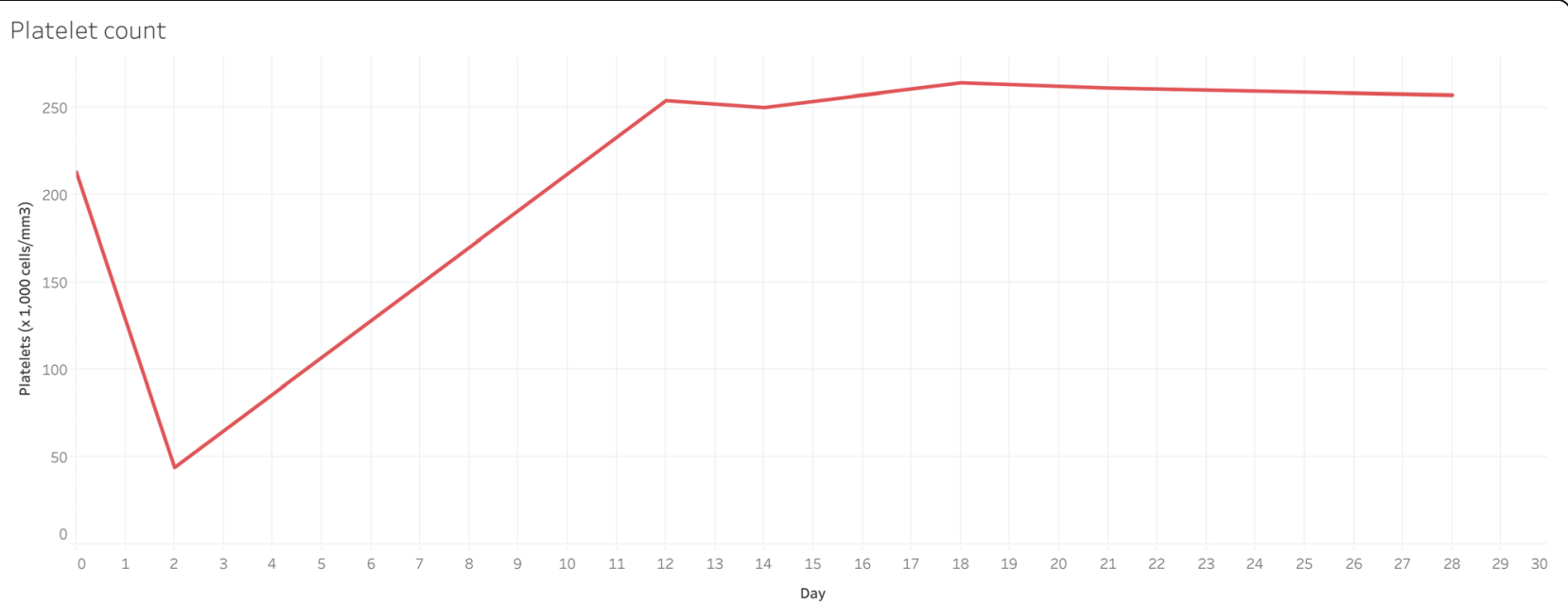

Fig. 3 Platelet count from postoperative day 1 to day 28. The red line represents the evolutions of the platelet count 
significantly lower than their counterparts with aHUS (LDH 1325-3940 IU/L and creatinine 3.9-7.6 mg/dL). On the other hand, women with HELLP syndrome present higher hemoglobin (7.3-10.4) and platelets (47,000-82, 000) [8].

Our patient had $1398 \mathrm{IU} / \mathrm{L} \mathrm{LDH}$, creatinine $(6.9 \mathrm{mg} /$ $\mathrm{dL})$, hemoglobin $(7.80 \mathrm{~g} / \mathrm{dL})$ and platelets $(44.000$ cells/ $\mathrm{mm}^{3}$ ). Also, HELLP syndrome and preeclampsia tend to resolve once the patient delivers her baby. The elements mentioned above were all in favor of preeclampsia, triggering the complications of aHUS. However, the favorable evolution of the patient after just four hemodialysis sessions is not in favor of preeclampsia, triggering the complications of aHUS.

In the absence of confirmatory genetic test results or kidney biopsy to demonstrate the pathology of thrombotic microangiopathy, the diagnosis of aHUS remains presumptive. We recognize that the clinical and lab criteria are not ideal; however, in most hospitals in developing countries, these are readily available and can help inform clinicians as they make time-sensitive decisions.

aHUS presents as a triad of MAHA, thrombocytopenia, and acute renal failure and can lead to hypertension and extrarenal organ dysfunction $[9,10]$. Kidney injury is the result of lesions to endothelial cells by the membrane attack complex, C3a, and C5a. When these lesions affect endothelial cells of preglomerular arterioles, they can lead to the dysfunction of the juxtaglomerular apparatus and subsequently to severe but unstable hypertension.

aHUS, unlike "typical" hemolytic uremic syndrome, is not caused by the Shiga toxin and is not preceded by hemorrhagic diarrhea. The prodomeless aHUS is due to a defect in the alternative complement pathway regulation [9]. The alternative complement pathway is regulated by proteins found in the plasma and on the surface of host cells. Mutations of regulatory proteins predispose pregnant women to develop aHUS and are responsible for the evolution of HELLP syndrome or preeclampsia to aHUS in pregnant women [10].

The C3a and C5a released in the kidney can equally leak into the general circulation and stimulate the release of histamine by basophils causing lesions of non-renal end organs such as the brain, the retina, the bronchus, the intestine, the pancreas, and serous membranes [9]. MAHA in aHUS results from mechanical injury of erythrocytes as they go through stenotic arterioles and capillaries. The degree of hemolysis depends on the severity of the stenosis in the arterioles and capillaries. Consequently, it is not uncommon for patients with aHUS to present without MAHA when the stenosis is minimal [9]. The last sign of the aHUS triad, thrombotic thrombocytopenia, results from the consumption of platelets.

It is difficult to ascertain the diagnosis of aHUS, and delays in diagnosis and treatment can be life-threatening
$[2,9]$. The results of molecular tests can take weeks to be available, and they might return false negatives. In practice, patients with TMA are treated with plasma exchange therapy until all non-aHUS causes of TMA have been excluded. As soon as all non-aHUS causes of TMA have been eliminated, aHUS is retained as the diagnosis, and the patient is switched to complement therapy [9]. The reason being that plasma therapy is ineffective in aHUS patients with mutations of complement system regulatory membrane proteins. Additionally, overall dialysis free survival at one year of aHUS patients treated with plasma therapy is only $40 \%$ [9]. Unlike plasma therapy, complement therapy is effective in all aHUS cases, indiscriminate of the membrane protein mutations, and failure of the complement therapy should prompt the reevaluation of the diagnosis [11]. Patients are put on eculizumab, a humanized monoclonal antibody of complement $\mathrm{C} 5$, once a week for five weeks, then fortnightly subsequently [9].

Fortunately, the evolution was favorable after hemodialysis in this case. Clinicians must be able to recognize the signs of TMA early on and to narrow down the diagnosis to aHUS. However, governments must invest more in the health system to provide underresourced physicians with the tools to conveniently manage diseases such as aHUS.

\section{Abbreviations}

aHUS: atypical Hemolytic Uremic Syndrome; MAHA: Microangiopathic Hemolytic Anemia; TMA: Thrombotic Microangiopathy; TTP: Thrombotic Thrombocytopenic Purpura

\section{Acknowledgments}

The authors wish to acknowledge the contributions of Léon Tshilolo, Augustin Longo, Wilfrid Mbombo, and Olga Djoutsop for their material support.

\section{Authors' contributions}

MT and USK: Conceptualization, data curation, formal analysis, visualization, writing - original draft, writing - review and editing; $C T$ and FM: Investigation, methodology, project administration, supervision, writing - review and editing. All authors read and approved the final manuscript.

Funding

Not applicable.

\section{Availability of data and materials}

The datasets used and/or analyzed during the current study are available from the corresponding author on reasonable request.

Ethics approval and consent to participate

Ethics approval was granted by the institutional review board of Centre Hospitalier Monkolé, and consent was obtained from the patient.

\section{Consent for publication}

Written informed consent was obtained from the patient for publication of this case report and any accompanying images. A copy of the written consent is available for review by the Editor of this journal.

Competing interests

The authors declare that they have no competing interests. 


\section{Author details}

'Department of Obstetrics and Gynecology, Centre Hospitalier Mère-Enfant (CHME) Monkolé, Kinshasa, Democratic Republic of Congo. ${ }^{2}$ Faculty of Medicine, Université Notre-Dame du Kasayi, Kananga, Democratic Republic of Congo. ${ }^{3}$ Faculty of Medicine, Université Technologique Bel Campus, Kinshasa, Democratic Republic of Congo. ${ }^{4}$ Faculty of Medicine, Université de Kinshasa, Kinshasa, Democratic Republic of Congo.

Received: 11 September 2019 Accepted: 17 August 2020

Published online: 27 August 2020

\section{References}

1. Coppo P, Gay J, Veyradier A. Une microangiopathie thrombotique. Hématologie. 2013;19:297-307.

2. Gupta M, Feinberg BB, Burwick RM. Thrombotic microangiopathies of pregnancy: differential diagnosis. Pregnancy Hypertens. 2018;12:29-34.

3. Birkhoelzer S, Belcher A, Peet H. Diagnostic dilemma: severe thrombotic microangiopathy in pregnancy. J Intensive Care Soc. 2017;18:348-51.

4. Ouzeddoun N, Rhouh H, Benamar L, Ezaitouni F, Bayahia R, Al Hamany Z, et al. Le syndrome hémolytique et urémique à propos de 50 cas. Médecine de Magrheb. 1997;63:21-6.

5. George JN, Nester CM, Mclntosh JJ. Syndromes of thrombotic microangiopathy associated with pregnancy. Hematol Am Soc Hematol Educ Program. 2015;2015:644-8.

6. Cines DB, Levine LD. Thrombocytopenia in pregnancy. Hematol Am Soc Hematol Educ Program. 2017;2017:144-51.

7. Braunthal S, Brateanu A. Hypertension in pregnancy: pathophysiology and treatment. SAGE Open Med. 2019;7. https://doi.org/10.1177/ 2050312119843700.

8. Burwick RM, Moyle KA, Gupta M. Pregnancy-associated atypical hemolytic uremic syndrome: some answers. Am J Obstet Gynecol. 2019;220:S397-8.

9. Tsai H-M. Atypical hemolytic uremic syndrome: beyond hemolysis and uremia. Am J Med. 2019;132:161-7.

10. Tsai H-M, Kuo E. In reply: from gestational hypertension and preeclampsia to atypical hemolytic uremic syndrome. Obstet Gynecol. 2016;128:657-8.

11. Legendre CM, Licht C, Muus P, Greenbaum LA, Babu S, Bedrosian C, et al. Terminal complement inhibitor eculizumab in atypical hemolytic-uremic syndrome. N Engl J Med. 2013;368:2169-81.

\section{Publisher's Note}

Springer Nature remains neutral with regard to jurisdictional claims in published maps and institutional affiliations.

Ready to submit your research? Choose BMC and benefit from:

- fast, convenient online submission

- thorough peer review by experienced researchers in your field

- rapid publication on acceptance

- support for research data, including large and complex data types

- gold Open Access which fosters wider collaboration and increased citations

- maximum visibility for your research: over $100 \mathrm{M}$ website views per year

At $\mathrm{BMC}$, research is always in progress.

Learn more biomedcentral.com/submissions 